This is the final peer-reviewed accepted manuscript of

NASCIMBENE, JURI; Marini Lorenzo: Epiphytic lichen diversity along elevational gradients: Biological traits reveal a complex response to water and energy. JOURNAL OF BIOGEOGRAPHY, 42. 0305-0270

DOI: $10.1111 /$ jbi.12493

The final published version is available online at: $h$ ttp://dx.doi.org/10.1111/ibi.12493

Rights / License:

The terms and conditions for the reuse of this version of the manuscript are specified in the publishing policy. For all terms of use and more information see the publisher's website.

This item was downloaded from IRIS Università di Bologna (https://cris.unibo.it/)

When citing, please refer to the published version. 


\title{
Epiphytic lichen diversity along elevational gradients: biological traits reveal a complex response to water and energy
}

\author{
Juri Nascimbene $e^{1,2 \star}$ and Lorenzo Marini ${ }^{3}$
}

${ }^{1}$ Natural Sciences Museum of South Tyrol, 39100 Bolzano, Italy, ${ }^{2}$ Department of Life Sciences, University of Trieste, 34100 Trieste, Italy, ${ }^{3}$ Department of Agronomy, Food, Natural Resources, Animals and the Environment (DAFNAE), University of Padova, 35020 Legnaro, Padova, Italy
${ }^{*}$ Correspondence: Juri Nascimbene, Natural Sciences Museum of South Tyrol, via Bottai 1, 39100 Bolzano, Italy.

E mail: junasc@libero.it

\begin{abstract}
Aim Patterns of epiphytic lichen diversity along elevational gradients covering the range of Norway spruce forests were analysed. The roles of water and energy variables in shaping the observed species elevation relationship were tested, as well as how growth form and photobiont type distribution varied along the gradient.
\end{abstract}

Location South Tyrol, northern Italy.

Methods Eight sites were selected spanning the elevational range of spruce forests (900 $1900 \mathrm{~m}$ a.s.l.) and the regional rainfall gradient. At each site, a pair of forest stands (one mature even aged and one multilayered) was selected at three elevation steps. Epiphytic lichens were surveyed according to European guidelines for lichen diversity monitoring. Explanatory variables indicative of both forest structure and climate were included in the models.

Results A positive relationship was found between number of species and ele vation. This reflected the physiological response of epiphytic lichens to the main climatic factors, trait selection being the mechanism that determined the response at community level. Nonlinear species temperature and trait temper ature relationships predicted that major changes may be expected in the inter mediate part of the gradient. Lichens with a Trentepohlia algal partner were more frequent at lower elevations and proved to be sensitive to environmental factors indicative of forest structure. Lichen growth forms had contrasting pat terns related to temperature, crustose species richness being enhanced by increasing values, and alectorioid and foliose lichens by decreasing values. Alectorioid lichens were also negatively influenced by rainfall.

Main conclusions In a climate change scenario, lichen diversity in alpine regions will probably not benefit from an increase in air temperature in the same way as flowering plants. Monitoring variations in the proportions of growth form and photobiont type may represent a tool for detecting the effects of climate change on lichen species.

\section{Keywords}

Alpine spruce forests, climate change, elevational diversity gradient, energy, forest structure, Italy, lichen growth form, photobiont type, species richness, trait selection.

\section{INTRODUCTION}

Elevational gradients are a suitable model template for pre dicting the potential effect of temperature warming on plant and animal communities because they encompass several clines in climatic factors over a relatively short distance
(Lomolino, 2001; Körner, 2007). Regarding the predictive power of climate effect on plant diversity (Hawkins et al., 2003), the water energy dynamics theory has shown the potential to become a possible unifying theory (O'Brien, 1993, 2006; Vetaas, 2006), at least for modelling tree species richness (Bhattarai \& Vetaas, 2003; Field et al., 2005). The 
interaction between energy and water is known to be an important driver of diversity patterns of several taxonomic groups (Whittaker et al., 2007), their effects being dependent on latitude, i.e. at higher latitudes energy is the key limiting component of the interaction, whereas at lower latitudes water is the key limiting component (Hawkins et al., 2003). Mountain environments provide interesting study areas for exploring the relationship between water variables, energy variables and species diversity along vertical (elevational) gra dients (Bhattarai \& Vetaas, 2003, 2006; Banya et al., 2010; Marini et al., 2011a), which might be expected to resemble the broader latitudinal gradient.

Epiphytic lichens are among the most climate sensitive organisms, and evaluation of their diversity patterns along elevational gradients may provide early warning signs regarding loss of forest diversity and ecosystem functions as a result of climate change. There is mounting evidence that changes in temperature and rainfall can severely affect the structure of epiphytic communities, leading to the local extinction of several species (e.g. Aragón et al., 2012). The poikylohydric nature of lichens provides the basis for their different sensitivity to both water and energy compared with vascular plants. Both factors directly control relevant ecophysiological processes influencing growth rates and spe cies distribution (Insarov \& Schroeter, 2002). In particular, their physiology is closely coupled with ambient tempera ture and moisture conditions (Green et al., 2008), which influence thallus water saturation and desiccation. Increas ing ambient temperature may negatively affect lichens because of increased respiratory carbon losses (Schroeter et al., 2000), especially when it does not reflect water avail ability. Despite these predicted effects, the relationship between climatic factors and species richness along eleva tional gradients is still poorly known for lichens compared with vascular plants and animals.

The response of lichen communities to climatic factors is likely to be mediated by different functional traits (e.g. photobiont type and growth form) that determine the per formance of the species under given environmental condi tions (Diaz \& Cabido, 2001; Giordani et al., 2012; Rapai et al., 2012). Photobiont type and thallus growth forms are among the most responsive traits that account for large scale patterns of lichen diversity (Ellis \& Coppins, 2006, 2010; Marini et al., 2011b); for example, lichens with a
Trentepohlia algal partner are enhanced by increasing tem peratures (van Herk et al., 2002; Aptroot \& van Herk, 2007), lichens with a crustose growth form are expected to resist drought events because of desiccation tolerance, while those with a fruticose filamentose growth form (i.e. alector ioid lichens) suffer from excessive rewetting that depresses net assimilation (Coxson \& Coyle, 2003; Stevenson \& Cox son, 2007).

We analysed patterns of lichen diversity along steep ele vational gradients covering the range of managed spruce dominated forests. To test the water energy dynamics the ory on lichen diversity, along with a temperature gradient we also accounted for a regional gradient of rainfall to obtain orthogonal gradients in rainfall and temperature. Our hypothesis was that temperature is one of the main drivers of lichen diversity and trait distribution along the elevational gradient. Indeed, because of their poikylohydric nature, lichens are expected to be particularly sensitive to high temperatures, which influence the process of rewetting and thallus water content, inducing frequent and severe desiccation events. On this basis, a positive species eleva tion relationship was expected. Moreover, water availability is expected to interact with energy, i.e. the negative effect of high temperatures on species richness may be stronger in relatively arid areas than in wetter areas (a modified conjecture of Hawkins et al., 2003; see also Bhattarai \& Vetaas, 2003; McCain, 2007). We also tested whether growth form and photobiont type modified the species ele vation relationship. Firstly, a variety of responses to water and energy are expected for the different growth forms; crustose species are more resistant to high temperatures because of their capacity to withstand drought events, whereas foliose and alectorioid/fruticose growth forms are more desiccation sensitive. Secondly, lichens with a Tren tepohlia algal partner are expected to be more frequent in the lower part of the elevational gradient, being favoured by higher temperatures.

\section{MATERIALS AND METHODS}

\section{Study area}

The study was conducted in the alpine region of South Tyrol (northern Italy), which extends over 740,000 ha (Fig. 1a). The
Figure 1 (a) Study area, (b) distribution of the elevational gradients, and (c) scheme of the sampling design used to investigate epiphytic lichen diversity along elevational gradients in the South Tyrol, northern Italy. DEM, digital elevation model.

climate is largely influenced by elevation, ranging from tem perate conditions in the Adige Valley area, with a mean annual temperature of $1112^{\circ} \mathrm{C}$, to alpine tundra conditions above $1700 \mathrm{~m}$ above sea level (a.s.l.), with a mean annual tempera ture of $23^{\circ} \mathrm{C}$. Precipitation varies across the region, ranging from $<600$ to $1400 \mathrm{~mm} \mathrm{yr}^{-1}$ according to both elevation and a geographical gradient. Conditions are driest in the east west orientated Venosta Valley in the western part of the study area, and wettest in the central northern and eastern parts of the study area. Given the high geological diversity of the study area, the bedrock varies from hard siliceous to metamorphic, porphyric and carbonatic rocks, while soils are usually podsols and rendzinas (on calcareous bedrock).

Between 600 and $2100 \mathrm{~m}$ a.s.l. the landscape is dominated by forests that cover an area of 370,000 ha, of which $52 \%$ are spruce forests that are all managed for timber production in even aged or multilayered, uneven aged, stands. In both cases, management is based on progressive thinning and har vesting $\left(1.6 \mathrm{~m}^{3} \mathrm{ha}^{-1} \mathrm{yr}^{-1}\right)$ of mature trees.

\section{Sampling design}

Eight sites were selected (Fig. 1b) on the basis of the regional forest database, matching the requirement of containing spruce dominated forests within the whole elevation range of this forest type (900 $1900 \mathrm{~m}$ a.s.l.). The site selection spanned the entire regional rainfall gradient (c. $6001200 \mathrm{~mm} \mathrm{yr}^{-1}$ ).

At each site, a pair of forest stands was selected at three different elevation steps (900 $1200 \mathrm{~m}$ a.s.l., $14001600 \mathrm{~m}$ a.s.l. and $18001900 \mathrm{~m}$ a.s.l.), comprising one even aged mature stand and one multilayered stand that included mature trees, making a total of six stands at each site (Fig. 1c). In each forest stand, a $13 \mathrm{~m}$ radius plot was set out randomly, within which the species identity and diame ter at breast height (d.b.h.) of all living trees (diameter $>15 \mathrm{~cm}$ ) were recorded, as well as geographical position, elevation, aspect and slope (Table 1). In each plot, five mature spruce (Picea abies (L.) H.Karst.) trees were selected randomly for the lichen survey, for a total of 240. The lichen survey was conducted according to the European guidelines for lichen monitoring (Asta et al., 2002). Lichen diversity was sampled using four standard frames of $10 \mathrm{~cm} \times 50 \mathrm{~cm}$ as sampling grids, subdivided into five $10 \mathrm{~cm} \times 10 \mathrm{~cm}$ quadrats, which were attached to the tree trunk at the cardi nal points, with the shorter lower side at $100 \mathrm{~cm}$ from the ground. Two additional standard frames were placed at the base of the trunk on north and south facing sides. All lichen species inside the frames, including sterile crustose lichens, were listed and their frequency was computed as the number of $10 \mathrm{~cm} \times 10 \mathrm{~cm}$ quadrats in which they occurred. The exhaustiveness of the sampling was tested for each elevation step using sample based accumulation curves (Gotelli \& Col well, 2001).

\section{Species identification}

When possible, lichens were identified in the field. However, in most cases species identification was based on the study

Table 1 General overview of the main topographic features of the study plots and variability and range of the explanatory variables (forest structure and climate) used to investigate epiphytic lichen diversity along elevational gradients in South Tyrol, northern Italy. For the variables indicative of forest structure, the general mean values are reported as well as those related to the two types of stands (even aged and multilayered).

\begin{tabular}{|c|c|c|c|}
\hline & Variable & Mean $\pm \mathrm{SD}$ & Range \\
\hline \multirow[t]{3}{*}{ Topography } & Elevation (m a.s.l.) & $1488 \pm 312.5$ & 9001900 \\
\hline & Aspect $\left(^{\circ}\right)$ & $215.5 \pm 137$ & 5360 \\
\hline & Slope $\left(^{\circ}\right)$ & $25.2 \pm 9.8$ & 544 \\
\hline \multirow[t]{16}{*}{ Forest structure } & Mean circumference of the plot $(\mathrm{cm})$ & $143.2 \pm 24.7$ & 100216 \\
\hline & Even aged stands & $159 \pm 20.8$ & 131216 \\
\hline & Multilayered stands & $127.4 \pm 17.2$ & 100157 \\
\hline & Circumference of sampled trees $(\mathrm{cm})$ & $185 \pm 32$ & 110270 \\
\hline & Even aged stands & $189.7 \pm 20.7$ & 158236 \\
\hline & Multilayered stands & $180.6 \pm 23.2$ & 147232 \\
\hline & Age of sampled trees (years) & $144 \pm 41$ & 65235 \\
\hline & Even aged stands & $141.2 \pm 42$ & 65234 \\
\hline & Multilayered stands & $146.5 \pm 40$ & 81235 \\
\hline & Basal area $\left(\mathrm{m}^{2} \mathrm{ha}^{-1}\right)$ & $66.9 \pm 18.2$ & 27.2108 .5 \\
\hline & Even aged stands & $65.4 \pm 17$ & 35103 \\
\hline & Multilayered stands & $68.5 \pm 17$ & 27.2108 .5 \\
\hline & $\%$ canopy closure & $74.8 \pm 3.9$ & 66.382 .9 \\
\hline & Even aged stands & $75.5 \pm 3.5$ & 6982.9 \\
\hline & Multilayered stands & $74.3 \pm 4$ & 66.382 \\
\hline & Stand type & & Even aged versus multilayered \\
\hline \multirow[t]{3}{*}{ Climate } & Mean annual temperature $\left({ }^{\circ} \mathrm{C}\right)$ & $4.9 \pm 1.9$ & 29.1 \\
\hline & Mean annual precipitation ( $\mathrm{mm})$ & $795.8 \pm 180.6$ & 5631182 \\
\hline & Annual solar radiation $\left(\mathrm{kWh} \mathrm{m}^{-2}\right)$ & $992.8 \pm 289.5$ & 602.21777 .2 \\
\hline
\end{tabular}


of specimens (c. 800) collected and stored in the personal herbarium of J.N. and in the herbarium of the Natural Sci ences Museum of South Tyrol (Bolzano, Italy). In particular, crustose lichens were identified in the laboratory using a dis secting and a biological microscope. Routine chemical spot tests were performed for most specimens. The identification of sterile crustose lichens (including all Lepraria species, c. 150 specimens) was based on standardized thin layer chro matography (TLC) analyses following the protocols of White \& James (1985) and Orange et al. (2001). Nomenclature of lichen species mainly follows Nimis \& Martellos (2008).

\section{Explanatory variables}

\section{Forest structure}

We focused on the response of lichen richness to climate fac tors but we also took into account the variability of the for est habitat quality, which may be indicative of the effects of forest management. According to our sampling design, each plot was assigned to one of the two types of forest structure: even aged mature stands or multilayered stands that included mature trees (categorical variable), the number of plots for each forest type being equal. Canopy closure was estimated using a spherical densitometer, by averaging 20 measure ments recorded at the four cardinal points of each tree selected for the lichen survey. Mean tree circumference was calculated by averaging the circumference of all the trees recorded within each plot. Basal area, an indicator of both substrate amount and forest density, was calculated on the basis of the circumference measurements of all the trees within each plot. For each tree selected for the lichen inven tory, the circumference was measured and its age determined by extracting cores using a Pressler type increment borer at a height of $1.30 \mathrm{~m}$. Because the effect of climate related factors was the main interest, plots placed in the three elevation steps were chosen for comparable forest structure variables. However, by keeping tree diameter uncorrelated with eleva tion, tree age covaried with elevation as a result of different tree growth rates along the elevational gradient.

\section{Climate}

Mean annual precipitation was considered as an indicator of water availability. Mean annual temperature and solar radia tion, considered as a measure of potential light available for photosynthesis (Table 1), were used as a measure of available energy. Mean annual temperature (1980 2011), using ordin ary kriging with external drift (Benavides et al., 2007), was interpolated from 84 meteorological stations, evenly scattered throughout and outside the study area at elevations ranging from 200 to $2000 \mathrm{~m}$ a.s.l. (see Marini et al., 2011a for more details). The fitted temperature was first estimated from a simple regression with elevation, and the residuals were then interpolated using ordinary kriging and the interpolated residuals summed with the fitted temperature from the regression with elevation. Mean annual precipitation was interpolated using ordinary kriging from 88 meteorological stations evenly scattered throughout the study area. The geo statistical interpolations were computed using the Kriging Interpolator 3.2 extension for ARCVIEw 3.2 (ESRI, Redlands, CA, USA). For each plot, the annual potential solar radiation was calculated using the digital elevation model (DEM) of the study area with a resolution of $25 \mathrm{~m}$ employing ARC VIEW 3.2.

\section{Statistical analyses}

\section{Species composition}

As well as environmental factors, geographical position is very likely to affect local patterns of species composition (Borcard et al., 1992). In order to elicit the spatial gradient, the potential spatial autocorrelation was taken into account using Moran's eigenvector map method (MEM; Dray et al., 2006). Spatial eigenvector mapping is based on the premise that the spatial relationships among data points can be trans lated into explanatory variables, which capture spatial effects at different spatial scales (Dray et al., 2006; Griffith \& Peres Neto, 2006). Eigenvectors from these connectivity matrices represent the decompositions of Moran's I statistic into all mutually orthogonal maps that can be generated from a given connectivity matrix (Griffith \& Peres Neto, 2006). There are several possibilities for building connectivity matri ces, but the implementation suggested in Dray et al. (2006) and the procedure suggested by Eisenlohr (2014) were fol lowed. The spatial weights were quantified using the minmax methods based on Kelejian \& Prucha (2010) and the MEMs were computed using the scores.listw() function. A forward selection (Blanchet et al., 2008) was performed separately for the environmental variables (elevation and management type) and MEMs $(P \leq 0.05)$ to select significant predictors that accounted for most of the variation in species composi tion. The significant variables were then analysed further by means of a variation partitioning approach to determine the relative influence of environmental variables and spatial structure on species composition (Legendre et al., 2012). The variation in species composition was decomposed using a series of (partial) redundancy analysis (RDA), implemented in the R package vegan (Oksanen et al., 2013). All RDAs were tested for significance with a Monte Carlo permutation test (1000 runs). The total variation in species composition was divided into three components: the pure effect of abiotic environment, the pure effect of space, and their joint effect. For the species composition analysis the species by site, and not the species by tree, matrix was used, as trees within the same plot were too close to each other to perform the spatial analysis.

An indicator species analysis (ISA; Dufrêne \& Legendre, 1997) was used to determine how strongly each species was associated with each elevation step and forest type. For each species, the indicator value (INDVAL) ranges from 0 (no 
indication) to 100 (maximum indication). The statistical sig nificance of INDVAL was tested by means of a Monte Carlo test, based on 10,000 randomizations. ISA and Monte Carlo tests were performed with PC ORD (McCune \& Mefford, 1999).

\section{Determinants of species richness and traits incidence}

A mixed model (Zurr et al., 2009) was used to test the effect of climatic and forest structure on lichen species richness and trait distribution. Tree level species richness and the incidence ( $\%$ of species) of selected biological traits (Table 1 ) were considered as response variables that could be indicative of the adaptation to climatic conditions (Giordani et al., 2012). Particular focus was placed on the photobiont type, analysing the incidence of lichens with a Trentepohlia algal partner (Aptroot \& van Herk, 2007; Marini et al., 2011b), and on thallus growth forms (Giordani et al., 2012), analy sing the incidence of crustose, alectorioid/fruticose and foli ose lichens. Biological traits of the species were retrieved from Nimis \& Martellos (2008). The various climatic and forest variables described in Table 1 were included as fixed effects, and plot within elevation step within gradient as a random factor, as follows (random intercept model): response variable, fixed effects: environmental variables, ran dom effects: gradient/elevation step/plot.

The random structure accounted for the spatial depen dence between trees in our hierarchical sampling design. The interaction between rainfall and temperature was included in order to test the conjecture of Hawkins et al. (2003), that the effect of rainfall will be stronger at lower (warmer) eleva tions, and a modified conjecture, that the negative effect of temperature will be stronger in the arid part of our sample area.

Because of the relatively low number of replicates and the relatively high number of potential predictors, multimodel inference within an information theoretic framework was used to evaluate the role of the selected variables (Table 1) in explaining patterns of epiphytic lichen species richness and trait incidence (Burnham \& Anderson, 2002). All selected vari ables corresponded to meaningful ecological predictors of lichen species richness patterns. Severe collinearity was absent in our dataset, the only two variables that were highly corre lated $(r>0.50)$ being age and temperature (see Appendix S1 in Supporting Information). This correlation was unavoidable as trees were selected of comparable size along the elevational gradient. Both variables were included in the multimodel inference analysis as they were both expected to have an important effect on lichens. The fit of all the possible candidate models obtained by the combination of the predictors described above was compared using second order Akaike's information criterion corrected for small samples (AICc). The AICc is a measure of relative model fit, proportional to the likelihood of the model and the number of parameters used to generate it; the best fitting model is the one with the lowest AICc. In a set of $n$ models, each model can be ranked by using its difference in $\mathrm{AICc}$ score with the best fitting model $\left(\triangle \mathrm{AICc}_{i} \quad \mathrm{AICc}_{i}-\mathrm{AICc}\right.$ minimum). The difference in AICc values indicates the relative support for the different models. A model is usually considered plausible if its $\triangle \mathrm{AICc}$ is below 2 (Burnham \& Anderson, 2002). For every model, an Akaike's weight $\left(w_{i}\right)$ was also calculated, in order to determine whether the model would be selected as the best fitting model if the data were collected again under identical circumstances (Burn ham \& Anderson, 2002). Akaike's weight should be interpreted as a measure of model selection uncertainty. The multimodel inference analyses were performed using the MuMIn package (Barton, 2010) implemented in R (R Development Core Team, 2011).

To test the assumptions of our mixed models, the normal ity and variance homogeneity of model residuals were checked. The potential residual spatial autocorrelation was also tested using Moran's $I$ and the correlog() function in the R package NCF (Bjornstad, 2013) on both geographical and ordination space distances (Diniz Filho et al., 2003). To obtain ordination space distances, detrended correspondence analysis (DCA) was used on a dataset based on the abun dance of all species on the 240 trees sampled. Many shared species yielded high statistical dependence and vice versa, i.e. there was species ordination space autocorrelation. The loca tion of sampling points in species ordination space will be almost as important as the geographical distance because this determines the statistical independence of species richness observations (Vetaas et al., 2014). All model diagnostics were performed on the plausible models $(\triangle \mathrm{AICc}<2)$ identified by the multimodel inference analysis (see Appendix S2).

\section{RESULTS}

\section{General results}

On 240 trees distributed in 48 plots, 124 lichen species (including five non lichenized fungi) occurred (see Appendix S3) with a frequency ranging from $0.4 \%$ to $76 \%$. Mean spe cies richness was $13.2 \pm 6.4$ (range 228 ).

Sixty three species were found at the lowest elevation step (900 $1200 \mathrm{~m}$ a.s.l.), 89 at the intermediate (1400 $1600 \mathrm{~m}$ a.s.l.) and 83 at the highest (1800 $1900 \mathrm{~m}$ a.s.l.). Sample based rarefaction curves indicated an equal exhaustiveness of the sampling among the three elevation steps (Fig. 2). The lowest elevation step shared 44 and 37 species with the inter mediate and highest steps, respectively; the latter two steps shared 63 species.

Seventy four species were crustose, 23 foliose and 27 fruti cose, including 14 alectorioid species (i.e. with a fruticose fil amentose thallus) belonging to the genera Bryoria, Evernia and Usnea. The mean percentage of crustose species was $49.7 \pm 25.7$ (range 0100 ), that of foliose species $34.3 \pm 18.1$ (range 0 86) and that of alectorioid species $8.5 \pm 8.4$ (range 0 50). One hundred and eleven species had chlorococcoid green algae and eight species had a Trentepohlia algal partner. The mean percentage of species with a Trentepohlia algal 


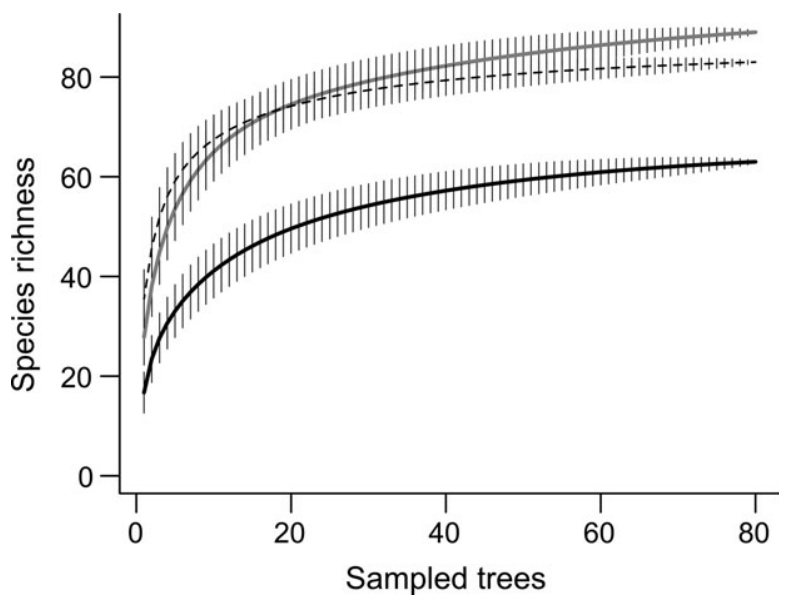

Figure 2 Sample based (tree) rarefaction curves within each elevation step used to investigate epiphytic lichen diversity along elevational gradients in the South Tyrol, northern Italy. Black line, elevation step between 900 and $1200 \mathrm{~m}$ a.s.l.; grey line, elevation step between 1400 and $1600 \mathrm{~m}$ a.s.l.; dotted line, elevation step between 1800 and $1900 \mathrm{~m}$ a.s.l.

partner was $5.7 \pm 9.3$ (range 050 ). The main reproductive strategy was by vegetative propagules ( 65 sorediate and 8 isi diate species), followed by sexual reproduction by ascospores (50 species) and thallus fragmentation (one species).

\section{Species composition}

In the RDA analysis, the separated forward selection proce dure resulted in two MEMs among the spatial variables, while only elevation was selected among the environmental variables $(P \leq 0.05)$, i.e. the species composition changed sig nificantly with elevation but also included some spatial auto correlation. The variation partitioning analysis indicated that the pure effects of space and elevation were $2 \%$ and $18 \%$, respectively, while the joint contribution was $5 \%$. The ISA revealed that $51 \%$ of the lichens were over represented in one of the three elevation steps (Appendix S3), with 33, 20 and 11 species associated with higher, intermediate and lower elevations, respectively.

\section{Determinants of species richness and incidence of traits along the entire elevational gradient}

Lichen species richness showed a linear positive relationship with elevation (Fig. 3a) and no support for an interaction between rainfall and temperature could be detected; multi model inference analyses are therefore presented without this interaction (Table 2). Along the whole elevational gradient, species richness was significantly explained by temperature, with a negative nonlinear effect resulting in a peak close to the lower end of the temperature gradient (Fig. 3b). A linear posi tive effect of solar radiation was also found, but no significant interaction could be detected between temperature and rain fall, nor any pure effect of rainfall (Table 2). Conversely, the effect of temperature on lichens with a Trentepohlia algal partner revealed that these species were more frequent at lower elevations (Fig. 3c), also because of their sensitivity to environ mental factors indicative of forest structure, being enhanced by increasing basal area and more competitive on young trees (a negative relationship with tree age).

Lichen growth forms had contrasting patterns in relation to temperature, the incidence of crustose species being enhanced by increasing values and that of alectorioid/fruti cose and foliose lichens by decreasing values (Fig. 3d,e,f, Table 2). Relationships for foliose and crustose lichens were nonlinear with a significant quadratic term. Alectorioid/fruti cose lichens were also negatively influenced by rainfall. Fac tors indicative of forest structure had only weak effects on the incidence of different lichen growth forms (Table 2).

No autocorrelation in the mixed model residuals consider ing both the geographical and ordination space (DCA scores) distances were detected, indicating that our models could explain the spatial and compositional autocorrelation of our response variables.

\section{DISCUSSION}

Patterns of epiphytic lichen diversity along steep elevational gradients in managed alpine spruce forests indicated that the influence of water and energy on poikylohydric organisms may result in species elevation relationships that differ from those of vascular plants and many other organisms (e.g. Rah bek, 1995; Marini et al., 2011a) where species richness declines with elevation or presents a hump shaped relation ship (cf. Banya et al., 2010). In contrast, a linear positive species elevation relationship was found, perhaps reflecting the fact that only a partial gradient (Nogués Bravo et al., 2008), avoiding both low and high elevation, was considered. However, the nonlinear relationship between lichen diversity, trait composition and temperature (i.e. the most meaningful climatic factor varying with elevation) indicated that the response of lichen species richness to temperature was rela tively non intense up to a certain level $\left(56^{\circ} \mathrm{C}\right.$ in our study) and then became very strong, i.e. even a slight temperature increase resulted in a reduction of species richness. This rela tionship may imply that, under climate warming scenarios, major changes could be expected in the intermediate part of the elevational gradient. This corroborates the hypothesis that many lichens will probably not benefit from an increase in air temperature in the same way as flowering plants (Insa rov \& Schroeter, 2002) and that several lichen species may be locally threatened by climate change (e.g. Ellis et al., 2007; Aragón et al., 2012).

The pattern of species richness and trait composition along the elevational gradient corresponded with a turnover in species composition occurring between the lower and the higher elevations. An increase in lichen diversity with eleva tion, associated with a substantial species turnover, has also been found in other geographical and environmental condi tions (e.g. Dietrich \& Scheidegger, 1997; McCune et al., 

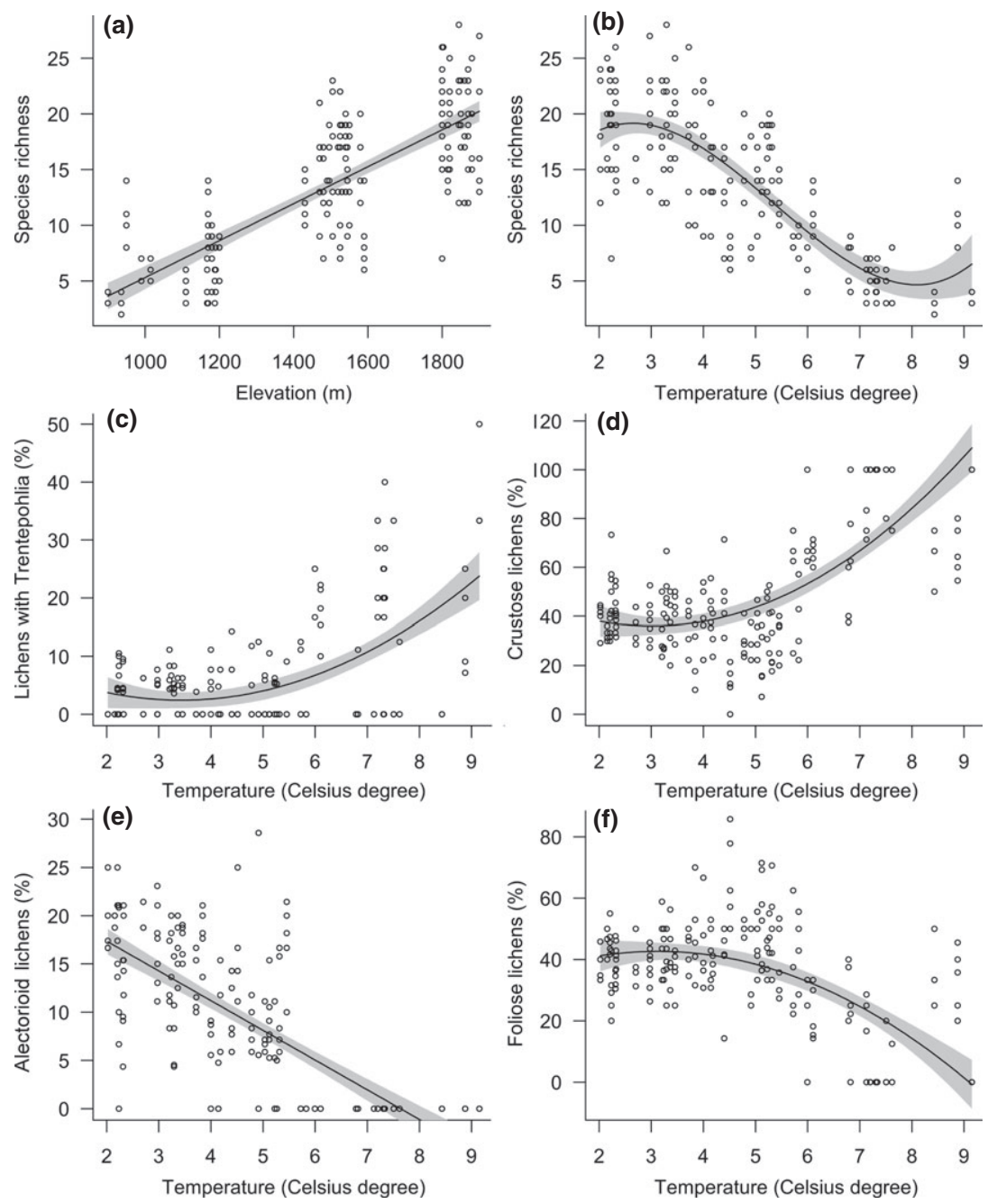

Figure 3 Scatterplots of the relationship between (a) elevation and lichen species richness, (b) mean annual temperature and lichen species richness, (c) mean annual temperature and the percentage of lichen species with Trentepohlia as algal partner, and (b f) mean annual temperature and percentage of lichens with different growth forms, (d) crustose, (e) alectorioid (i.e. fruticose filamentose) and (f) foliose, in the study of epiphytic lichen diversity along elevational gradients in the South Tyrol, northern Italy. Ninety five per cent confidence intervals are shown.

1997; Cobanoglu \& Sevgi, 2009), corroborating the hypothe sis that the species elevation relationship reflects the physio logical response of these organisms to the main climatic factors. Our study supports this view, revealing that trait selection is the mechanism that determines the response at community level.

The climatic results only partially confirmed our hypothe sis related to the conjecture of Hawkins et al. (2003), that the effect of rainfall should be stronger at lower (warmer) elevations, and to a modified conjecture, that the negative effect of temperature will be stronger in the arid part of our sample area, as no interactive effect between temperature and precipitation was found. The lack of a pure effect of pre cipitation on species richness patterns suggests that a larger rainfall gradient (e.g. Aragón et al., 2012) should be spanned to test this hypothesis. The only signal of a relevance to the rainfall gradient derives from its negative influence on the incidence of alectorioid lichens, which fully reflects their par ticular ecophysiological requirements, being hindered by excessive wetting that depresses net assimilation (Stevenson \& Coxson, 2007).

Temperature was the main driver of lichen diversity and trait selection along the elevational gradient. The negative relationship with species richness reflects the negative effects of increasing temperature on key ecophysiological processes, such as an increase of respiratory carbon loss (Schroeter et al., 2000) that may limit the distribution of many species. Moreover, an increase in temperature is usually associated with a decrease in relative air humidity, resulting in faster desiccation rates of poikylohydric organisms, which hinders photosynthetic activity (Insarov \& Schroeter, 2002). The positive species solar radiation relationship predicts that these effects are likely to be exacerbated by low solar radia tion reducing the availability of light for photosynthetic activity.

The adaptation of lichen communities to a temperature regime is mediated by a trait selection that involves both the photobiont and thallus growth forms. Concerning the photobiont, lichens in symbiosis with Trentepohlia algae are more adapted to warm climates, confirming that the photobiont type can mediate the response to global warm ing (van Herk et al., 2002; Aptroot \& van Herk, 2007; Marini et al., 2011b). However, the contribution of these lichens to community composition is not only determined by the temperature regime but also by some forest attri butes. In particular, the positive relationship between the 
Table 2 Sum of model weights $\left(\Sigma w_{i}\right)$ for each predictor used along the whole gradient for (a) all species and (b e) the trait groups, separately (b, algal partner; $c$ e, thallus growth forms) in the investigation of epiphytic lichen diversity along elevational gradients in the South Tyrol, northern Italy. The sum can vary between 0 and 1 . The variables that presented values close to 1 are those more supported by the multi model inference analysis. Variables with sum $>0.65$ are shown in bold.

\begin{tabular}{|c|c|c|c|c|c|c|c|c|c|c|c|}
\hline & Age & Circ tree & Basal & Canopy & Circ plot & Stand type & $\mathrm{Rad}$ & Precip & Temp & $\mathrm{Temp}^{2}$ & Temp $^{3}$ \\
\hline \multicolumn{12}{|l|}{ (a) All species } \\
\hline$\Sigma w_{i}$ & 0.45 & 0.26 & 0.27 & 0.26 & 0.30 & 0.25 & 0.69 & 0.27 & 0.91 & 0.93 & 0.93 \\
\hline $\begin{array}{l}\text { Averaged } \\
\text { parameters }\end{array}$ & 0.0053 & 0.0036 & 0.0368 & 0.0081 & 0.0008 & 2.542 & 0.0026 & 0.0053 & 9.4765 & 2.470 & 0.1533 \\
\hline \multicolumn{12}{|l|}{ (b) Trentepohlia } \\
\hline$\Sigma w_{i}$ & 0.79 & 0.54 & 0.69 & 0.26 & 0.33 & 0.48 & 0.28 & 0.39 & 0.43 & 0.52 & 0.71 \\
\hline $\begin{array}{l}\text { Averaged } \\
\text { parameters }\end{array}$ & 0.0332 & 0.02514 & 0.08534 & 0.0625 & 0.0143 & 1.7930 & 0.00195 & 0.0084 & 2.0809 & 0.0475 & 0.0483 \\
\hline \multicolumn{12}{|l|}{ (c) Foliose } \\
\hline$\Sigma w_{i}$ & 0.25 & 0.36 & 0.28 & 0.29 & 0.36 & 0.38 & 0.60 & 0.31 & 0.83 & 0.89 & 0.86 \\
\hline $\begin{array}{l}\text { Averaged } \\
\text { parameters }\end{array}$ & 0.0030 & 0.0323 & 0.0459 & 0.2747 & 0.0663 & 2.9809 & 0.0119 & 0.0085 & 56.5645 & 10.634 & 0.6014 \\
\hline \multicolumn{12}{|l|}{ (d) Crustose } \\
\hline$\Sigma w_{i}$ & 0.27 & 0.50 & 0.37 & 0.28 & 0.40 & 0.28 & 0.62 & 0.50 & 0.87 & 0.92 & 0.89 \\
\hline $\begin{array}{l}\text { Averaged } \\
\text { parameters }\end{array}$ & 0.0161 & 0.0492 & 0.1275 & 0.2848 & 0.1046 & 0.5607 & 0.0159 & 0.0230 & 80.230 & 15.2357 & 0.853 \\
\hline \multicolumn{12}{|c|}{ (e) Alectorioid/fruticose } \\
\hline$\Sigma w_{i}$ & 0.25 & 0.40 & 0.46 & 0.51 & 0.28 & 0.26 & 0.27 & 0.97 & 0.67 & 0.66 & 0.70 \\
\hline $\begin{array}{l}\text { Averaged } \\
\text { parameters }\end{array}$ & 0.0004 & 0.0048 & 0.0140 & 0.0806 & 0.0027 & 0.0118 & 0.0002 & 0.0133 & 3.1101 & 0.3375 & 0.0394 \\
\hline
\end{tabular}

Age, age of sampled trees (years); Circ tree, circumference of sampled trees $(\mathrm{cm})$; Basal, basal area $\left(\mathrm{m}^{2} \mathrm{ha}^{-1}\right)$; Canopy, \% canopy closure; Circ plot, mean circumference of the plot $(\mathrm{cm})$; Stand type, even aged mature stands versus multilayered stands; Rad, annual solar radiation $\left(\mathrm{kWh} \mathrm{m}^{-2}\right)$; Precip, mean annual precipitation $(\mathrm{mm})$; Temp, mean annual temperature $\left({ }^{\circ} \mathrm{C}\right)$.

proportion of lichens with a Trentepohlia algal partner and forest basal area predicts that dense stands are able to ful fil better the habitat requirements of this group of species, which have their photosynthetic optimum in shaded, warm situations (Sipman \& Harris, 1989; Nimis \& Tretiach, 1995). Their preference for young trees (negative relation ship with tree age) is likely to reflect the microhabitat requirements related to the crustose growth form of the trentepohlioid species included in our dataset. Crustose thalli develop undisturbed when the bark is smooth (i.e. on young trees) but undergo fragmentation and disintegra tion as the bark becomes wrinkled with increasing tree age and size.

Concerning the thallus growth form, our results indicate that crustose lichens are more resistant than foliose and fru ticose filamentose (i.e. alectorioid) species to increasing tem perature (see Acharya et al., 2011 for epiphytic orchids). Crustose lichens have a lower surface to volume ratio (i.e. less surface exposed to the atmosphere), resulting in a higher tolerance to desiccation, water loss being restricted to the upper exposed surface (Büdel \& Scheidegger, 2008). In con trast, the contribution of foliose and fruticose filamentose species to lichen diversity is higher in the lower part of the temperature gradient, reflecting their more rapid drying and wetting pattern that hinders these lichens surviving excessive evapotranspiration rates.

Our results add evidence to the sensitivity of epiphytic lichens to climate change (Insarov \& Schroeter, 2002; Ellis et al., 2007). This study found strong elevation dependence of epiphytic lichen diversity in spruce alpine forests that can be attributed to climatic factors controlling the main ecophysiological functions of these organisms. The mecha nism of trait selection drives the response to environmental filtering, providing a tool for detecting major shifts in lichen communities that reflect changes in climatic conditions.

\section{ACKNOWLEDGEMENTS}

The study was carried out as part of the project 'Biodiver sità, biomonitoraggio e conservazione dei licheni epifiti negli ambienti forestali della provincia di Bolzano', funded by the Autonomous Province of Bolzano (Ripartizione Diritto allo studio, Università e Ricerca Scientifica). The Forest Planning Office of the Autonomous Province of Bolzano is thanked for providing logistic and technical support; in particular we are grateful to Günther Unterthiner and his collabora tors. Francesco Bortignon, Philipp Oberegger, Martin Ste cher and Diego Ivan are thanked for their help during the fieldwork. Daniel Spitale contributed to the discussions and the sampling design, and Helmut Mayrhofer (University of Graz) and his collaborators helped us with species identifi cation, particularly with thin layer chromatography (TLC) analyses and critical crustose species. Mark Seaward (Uni versity of Bradford) checked the language of the revised manuscript. 


\section{REFERENCES}

Acharya, K.P., Vetaas, O.R. \& Birks, H.J.B. (2011) Orchid species richness along Himalayan elevational gradients. Journal of Biogeography, 38, 18211833.

Aptroot, A. \& van Herk, C.M. (2007) Further evidence of the effects of global warming on lichens, particularly those with Trentepohlia phycobionts. Environmental Pollution, 146, 293298.

Aragón, G., Martínez, I. \& García, A. (2012) Loss of epiphytic diversity along a latitudinal gradient in south ern Europe. Science of the Total Environment, 426, 188195.

Asta, J., Erhardt, W., Ferretti, M., Fornasier, F., Kirschbaum, U., Nimis, P.L., Purvis, W., Pirintsos, S., Scheidegger, C., Van Haluwyn, C. \& Wirth, V. (2002) Mapping lichen diversity as an indicator of environmental quality. Moni toring with lichens, monitoring lichens (ed. by P.L. Nimis, C. Scheidegger and P. Wolseley), pp. 273 279. Kluwer Academic Publishers, Dordrecht.

Banya, C.B., Solhøy, T., Gauslaa, Y. \& Palmer, M.W. (2010) The elevation gradient of lichen species richness in Nepal. Lichenologist, 42, 8396.

Barton, K. (2010) MuMIn: multi model inference. R package version [01317]. Available at: http://r forge.r project.org/ projects/mumin/.

Benavides, R., Montes, F., Rubio, A. \& Osoro, K. (2007) Geostatistical modelling of air temperature in a mountain ous region of northern Spain. Agricultural and Forest Meteorology, 146, 173188.

Bhattarai, K.R. \& Vetaas, O.R. (2003) Variation in plant spe cies richness of different life forms along a subtropical ele vation gradient in the Himalayas, east Nepal. Global Ecology and Biogeography, 12, 327340.

Bhattarai, K.R. \& Vetaas, O.R. (2006) Can Rapoport's rule explain tree species richness along the Himalayan eleva tion gradient, Nepal? Diversity and Distributions, 12, 373 378.

Bjornstad, O.N. (2013) ncf: spatial nonparametric covariance functions. R package version 1.1 5. Available at: http:// CRAN.R project.org/package $=$ ncf.

Blanchet, F.G., Legendre, P. \& Borcard, D. (2008) Forward selection of explanatory variables. Ecology, 89, 26232632.

Borcard, D., Legendre, P. \& Drapeau, P. (1992) Partialling out the spatial component of ecological variation. Ecology, 73, 10451055.

Büdel, B. \& Scheidegger, C. (2008) Thallus morphology and anatomy. Lichen biology (ed. by T.H. Nash III), pp. 4068 . Cambridge University Press, Cambridge, UK.

Burnham, K.P. \& Anderson, D.R. (2002) Model selection and multimodel inference: a practical information theoretic approach. Springer Verlag, Berlin.

Cobanoglu, G. \& Sevgi, O. (2009) Analysis of the distribu tion of epiphytic lichens on Cedrus libani in Elmali Research Forest (Antalya, Turkey). Journal of Environmen tal Biology, 30, 205212.
Coxson, D.S. \& Coyle, M. (2003) Niche partitioning and photosynthetic response of alectorioid lichens from subal pine spruce fir forest in north central British Columbia, Canada: the role of canopy microclimate gradients. Lichen ologist, 35, 157175.

Diaz, S. \& Cabido, M. (2001) Vive la difference: plant func tional diversity matters to ecosystem processes. Trends in Ecology and Evolution, 16, 646655.

Dietrich, M. \& Scheidegger, C. (1997) Frequency, diversity and ecological strategies of epiphytic lichens in the Swiss Central Plateau and the pre Alps. Lichenologist, 29, 237 258.

Diniz Filho, J.A.F., Bini, L.M. \& Hawkins, B.A. (2003) Spatial autocorrelation and red herrings in geographical ecology. Global Ecology and Biogeography, 12, 5364.

Dray, S., Legendre, P. \& Peres Neto, O. (2006) Spatial mod elling: a comprehensive framework for principal coordi nate analysis of neighbor matrices (PCNM). Ecological Modelling, 196, 483493.

Dufrêne, M. \& Legendre, P. (1997) Species assemblages and indicator species: the need for a flexible asymmetrical approach. Ecological Monographs, 67, 345366.

Eisenlohr, P.V. (2014) Persisting challenges in multiple mod els: a note on commonly unnoticed issues regarding collin earity and spatial structure of ecological data. Brazilian Journal of Botany, 37, 365371.

Ellis, C.J. \& Coppins, B.J. (2006) Contrasting functional traits maintain lichen epiphyte diversity in response to climate and autogenic succession. Journal of Biogeography, 33, 16431656.

Ellis, C.J. \& Coppins, B.J. (2010) Integrating multiple land scape scale drivers in the lichen epiphyte response: climatic setting, pollution regime and woodland spatial temporal structure. Diversity and Distributions, 16, 4352.

Ellis, C.J., Coppins, B.J., Dawson, T.P. \& Seaward, M.R.D. (2007) Response of British lichens to climate change sce narios: trends and uncertainties in the projected impact contrasting biogeographic groups. Biological Conservation, 140, 217235.

Field, R., O’Brien, E.M. \& Whittaker, R.J. (2005) Global models for predicting woody plant richness from climate: development and evaluation. Ecology, 86, 22632277.

Giordani, P., Brunialti, G., Bacaro, G. \& Nascimbene, J. (2012) Functional traits of epiphytic lichens as potential indicators of environmental conditions in forest ecosys tems. Ecological Indicators, 18, 413420.

Gotelli, N. \& Colwell, R.K. (2001) Quantifying biodiversity: procedures and pitfalls in the measurement and compari son of species richness. Ecology Letters, 4, 379391.

Green, T.G.A., Nash, T.H., III \& Lange, O.L. (2008) Physio logical ecology of carbon dioxide exchange. Lichen biology (ed. by T.H. Nash III), pp. 152 81. Cambridge University Press, Cambridge, UK.

Griffith, D.A. \& Peres Neto, P.R. (2006) Spatial modeling in ecology: the flexibility of eigenfunction spatial analyses. Ecology, 87, 26032613. 
Hawkins, B.A., Field, R., Cornell, H.V., Currie, D.J., Guégan, J. F., Kaufman, D.M., Kerr, J.T., Mittelbach, G.G., Obe rdorff, T., O’Brien, E.M., Porter, E.E. \& Turner, J.R.G. (2003) Energy, water, and broad scale geographic patterns of species richness. Ecology, 84, 31053117.

van Herk, C.M., Aptroot, A. \& van Dobben, H.F. (2002) Long term monitoring in the Netherlands suggests that lichens respond to global warming. Lichenologist, 34, 141154.

Insarov, G. \& Schroeter, B. (2002) Lichen monitoring and climate change. Monitoring with lichens, monitoring lichens (ed. by P.L. Nimis, C. Scheidegger and P. Wolseley), pp. 183 201. Kluwer Academic Publishers, Dordrecht.

Kelejian, H.H. \& Prucha, I.R. (2010) Specification and esti mation of spatial autoregressive models with autoregressive and heteroskedastic disturbances. Journal of Econometrics, 157, 5367.

Körner, C. (2007) The use of 'altitude' in ecological research. Trends in Ecology and Evolution, 22, 569574.

Legendre, P., Borcard, D. \& Roberts, D.W. (2012) Variation partitioning involving orthogonal spatial eigenfunction submodels. Ecology, 93, 12341240.

Lomolino, M.V. (2001) Elevation gradients of species den sity: historical and prospective views. Global Ecology and Biogeography, 10, 313.

Marini, L., Bona, E., Kunin, W.E. \& Gaston, K.J. (2011a) Exploring anthropogenic and natural processes shaping fern species richness along elevational gradients. Journal of Biogeography, 38, 7888.

Marini, L., Nascimbene, J. \& Nimis, P.L. (2011b) Large scale patterns of epiphytic lichen species richness: photobiont dependent response to climate and forest structure. Science of the Total Environment, 409, 43814386.

McCain, C.M. (2007) Could temperature and water availabil ity drive elevational species richness patterns? A global case study for bats. Journal of Biogeography, 16, 113.

McCune, B. \& Mefford, M.J. (1999) Multivariate analysis of ecological data, version 4.25. MjM Software, Gleneden Beach, OR.

McCune, B., Peck, D.J., Heiman, K. \& Will Wolf, S. (1997) Regional gradients in lichen communities of the southeast United States. Bryologist, 100, 145158.

Nimis, P.L. \& Martellos, S. (2008) ITALIC: the information system on Italian lichens, version 4.0. Available at: http:// dbiodbs.univ.trieste.it/italic/italic03.

Nimis, P.L. \& Tretiach, M. (1995) The lichens of Italy: a phytoclimatical outline. Cryptogamic Botany, 5, 199208.

Nogués Bravo, D., Araújo, M.B., Romdal, T. \& Rahbek, C. (2008) Scale effects and human impact on the elevational gradient species richness gradients. Nature, 453, 216220.

O'Brien, E.M. (1993) Climatic gradients in woody plant spe cies richness: towards an explanation based on an analysis of Southern Africa's woody flora. Journal of Biogeography, 20, 181198.
O'Brien, E.M. (2006) Biological relativity to water energy dynamics. Journal of Biogeography, 33, 18681888.

Oksanen, J., Blanchet, F.G., Kindt, R., Legendre, P., Min chin, P.R., O'Hara, R. B., Simpson, G.L., Solymos, P., Henry, M., Stevens, H. \& Wagner, H. (2013) vegan: community ecology package. R package version 2.010 . Available at: http://CRAN.R project.org/package=vegan.

Orange, A., James, P.W. \& White, F.J. (2001) Microchemical methods for the identification of lichens. British Lichen Soci ety, London.

R Development Core Team (2011) R: a language and envi ronment for statistical computing. R Foundation for Sta tistical Computing, Vienna. Available at: http://www.R project.org.

Rahbek, C. (1995) The elevational gradient of species rich ness: a uniform pattern. Ecography, 18, 200205.

Rapai, S.B., McMullin, R.T. \& Newmaster, S.G. (2012) The importance of macrolichen traits and phylogeny in forest community assemblage along a high elevation gradient in southwestern British Columbia. Forest Ecology and Man agement, 274, 231240.

Schroeter, B., Kappen, L., Schulz, F. \& Sancho, L.G. (2000) Seasonal variation in the carbon balance of lichens in the maritime Antarctic: long term measure ments of photosynthetic activity in Usnea aurantiaco atra. Antarctic ecosystems: models for wider ecological understanding (ed. by W. Davison, C. Howard Williams and P. Broady), pp. 258 262. Caxton Press, Christ church, New Zealand.

Sipman, H.J.M. \& Harris, R.C. (1989) Lichens. Tropical rain forest ecosystems (ed. by H. Leith and M.J.A. Werger), pp. 303 309. Elsevier, Amsterdam.

Stevenson, S.K. \& Coxson, D.S. (2007) Arboreal forage lichens in partial cuts: a synthesis of research results from British Columbia, Canada. Rangifer, 17, 155165.

Vetaas, O.R. (2006) Biological relativity to water energy dynamics: a potential unifying theory? Journal of Biogeog raphy, 33, 18661867.

Vetaas, O.R., Vikane, J.H., Saure, H.I. \& Vandvik, V. (2014) North Atlantic Islands with native and alien trees: are there differences in diversity and species area relationships? Journal of Vegetation Science, 25, 213225.

White, F.J. \& James, P.W. (1985) A new guide to microchemical techniques for the identification of lichen substances. Bulletin of the British Lichen Society, 57, 1 41.

Whittaker, R.J., Nogués Bravo, D. \& Araújo, M.B. (2007) Geographical gradients of species richness: a test of the water energy conjecture of Hawkins et al. (2003) using European data for five taxa. Global Ecology and Biogeogra phy, 16, 7689.

Zurr, A., Ieno, E.N., Walker, N., Saveliev, A.A. \& Smith, G.M. (2009) Mixed effects models and extensions in ecology with R. Springer, Berlin. 


\section{SUPPORTING INFORMATION}

Additional Supporting Information may be found in the online version of this article:

Appendix S1 Correlation matrix for the explanatory vari ables.

Appendix S2 Model diagnostics.

Appendix S3 List of the species recorded in this study.

\section{BIOSKETCHES}

Juri Nascimbene is an ecologist with a strong focus on conservation biology in terrestrial ecosystems. He investigates the impact of local and climatic factors on lichen diversity in forest ecosystems. His research interests in biogeography include the study of lichen diversity patterns along wide environmental gradients.

Lorenzo Marini is an ecologist at the University of Padova with a strong interest in conservation biology in terrestrial ecosystems. He investigates the impact of global change on biodiversity at different spatial scales.

Editor: Ole Vetaas 